\title{
Expression and role of microRNA 18b and hypoxia inducible factor-1 $\alpha$ in placental tissues of preeclampsia patients
}

\author{
SHENGLAN WANG, XUEMEI WANG, ZHANPING WENG, SHUPING ZHANG, HUI NING and BAOLAI LI \\ Department of Obstetrics, Qingdao Municipal Hospital, Qingdao, Shandong 266071, P.R. China
}

Received January 3, 2016; Accepted January 26, 2017

DOI: $10.3892 /$ etm.2017.5067

\begin{abstract}
Abnormal expression of hypoxia inducible factor- $1 \alpha(\mathrm{HIF}-1 \alpha)$ is closely associated with various diseases. By detecting the mRNA and protein expression levels of microRNA 18b (miR-18b) and HIF-1 $\alpha$ in placental tissues of preeclampsia (PE) patients and studying the effects of miR-18b on total cellular metabolic activity, migration and invasion in normal human trophoblast cell lines (HTR-8/SVneo), the present study aimed to investigate the effect of miR-18b on targeted regulation of HIF- $1 \alpha$ and its clinical significance in the development of PE. Expression levels of miR-18b and HIF-1 $\alpha$ mRNA in PE placental tissues were detected by reverse transcription-quantitative polymerase chain reaction and corresponding expression levels of HIF-1 $\alpha$ protein were analyzed by western blotting. miR-18b overexpression and inhibited miR-18b expression in HTR-8/SVneo cells, which were constructed by transfecting miR-18b mimic and inhibitor, respectively, were investigated and the total cellular metabolic activity, migration and invasion abilities in different groups of cells were compared. Expression levels of miR-18b were significantly reduced in PE placental tissues and miR-18b inhibitor-transfected HTR-8/SVneo cells, whereas the expression levels of HIF-1 $\alpha$ were significantly increased in PE placental tissues and significantly decreased in miR-18b mimic-transfected HTR-8/SVneo cells. Overexpression of miR-18b inhibited the expression of HIF-1 $\alpha$ and reduced the cell invasion, migration and viability of HTR-8/SVneo cells. However, inhibition of miR-18b expression promoted the expression of HIF- $1 \alpha$ and increased the cell invasion, migration and total cellular metabolic activity of HTR-8/SVneo cells. The present study indicated that abnormal expression of HIF-1 $\alpha$ exhibited in PE placental tissues was regulated by miR-18b. Furthermore miR-18b expression was demonstrated to affect cell invasion, migration and viability through target
\end{abstract}

Correspondence to: Dr Xuemei Wang, Department of Obstetrics, Qingdao Municipal Hospital, 5 Hongkang Middle Road, Qingdao, Shandong 266071, P.R. China

E-mail: bxv365@163.com

Key words: preeclampsia, microRNA 18b, hypoxia inducible factor- $1 \alpha$ regulation of HIF-1 $\alpha$. The results of the present study suggest that miR-18b and HIF-1 $\alpha$ may have important roles in the development of PE.

\section{Introduction}

Preeclampsia (PE), which is predominantly characterized by hypertension and proteinuria and is a pregnancy-specific disease that originates in the placenta, is a serious threat to maternal and perinatal life (1). Although PE is considered a common obstetric complication, the mechanism of pathogenesis remains to be fully elucidated. At present, the majority of studies suggest that abnormal differentiation and apoptosis in trophoblast cells results in cell dysfunction, changes in infiltration and spiral artery remodeling in trophoblast cells, which eventually leads to the occurrence of PE $(2,3)$. Thus, the dysfunction of trophoblast cells is considered an important cause of PE. MicroRNA (miRNA) are a class of endogenous and highly conserved non-coding small RNA, with the length from 18 to 24 nucleotides. The basic function of miRNA is to bind to the specific pairing bases of target mRNA [i.e., miRNA-specific binding to the 3' untranslated region (3'UTR) of target mRNA], causing degradation or translational repression of the target mRNA and promoting post-transcriptional gene silencing (4). Previous studies suggest that miRNA have important roles in various basic physiological processes, such as cell growth, differentiation, proliferation and apoptosis (5-7). Furthermore, previous studies have indicated a series of expression imbalances between miRNA and target genes in PE placental tissues, which have resulted in cell dysfunction in placental tissues; thus, abnormal expression levels of miRNA have been demonstrated to be closely related to the occurrence of PE in PE patients (8-10). miR18b (miR-18b) is involved in the regulation of multiple diseases. It has been reported that miR-18b has a role as a tumor suppressor gene by targeting the MDM2-p53 pathway in melanoma (11). Moreover, miR-18b is abnormally expressed in gastric cancer (12), breast cancer (13) and nasopharynx cancer (14). The present study indicated that miR-18b exhibited pathologically low expression levels in PE placentas; however, the pathological mechanism of miR-18b in the pathogenesis of PE remains poorly studied (15).

Hypoxia inducible factor-1 (HIF-1) is a key transcriptional regulatory factor that mediates cellular adaptation to hypoxia microenvironment (16). HIF-1 is overexpressed in various cancers and precancerous lesions and is considered to be the 
central initiating molecule of tumor angiogenesis (17). HIF-1 is a heterodimer that contains two subunits of HIF- $1 \alpha$ and HIF-1 $\beta$ (18). Taylor (19) revealed that, under normoxic conditions, prolyl hydroxyl-lase domain proteins (PHD) were able to hydroxylate the proline residues in the oxygen-dependent degradation domain of the $\mathrm{Q}$ subunit and subsequently enhance the affinity of HIF-1 $\alpha$ and tumor suppressor protein (von Hippel-Lindau protein), ultimately promoting the combination of HIF-1 $\alpha$ to a ubiquitin-dependent proteolytic enzyme complex to enzyme hydrolysis. In the case of hypoxia, PHD activity decreased and HIF-1 $\alpha$ rapidly gathered in the intracellular space, combined with $\beta$ isoforms and was transferred to the nucleus to promote the transcription of hypoxia-responsive genes. Ietta et al (20) reported that HIF-1 was the key molecular component that mediated the regulation of hypoxia during trophoblast cell-associated invasion and differentiation processes. A previous study indicated that the expression levels of HIF-1 $\alpha$ are sustained throughout pregnancy (21). HIF-1 $\alpha$ expression in villus tissues is significantly increased in weeks 8 to 10 of pregnancy, the time point at which the placental oxygen content is lower (22). Additionally, HIF-1 $\alpha$ expression has been revealed to exhibit a clear downward trend in weeks 10 to 12 of pregnancy, the time point at which the placental oxygen content increases and the invasion ability of trophoblast cells subsequently peaks as maternal-fetal circulation has been established (22). These changes have notable influences on the functions of trophoblast cells and the entire placenta, indicating that HIF-1 $\alpha$ may have a close relationship with the pathogenesis of PE.

In the present study, the expression levels of HIF-1 $\alpha$ and miR-18b in placental tissues were detected and the roles of HIF- $1 \alpha$ and miR-18b in PE were analyzed. The present findings may further elucidate the pathogenesis mechanism of $\mathrm{PE}$ and provide a novel theoretical basis for the treatment of PE.

\section{Materials and methods}

Tissue specimen collection. A total of 50 pregnant women consisting of $25 \mathrm{PE}$ patients and 25 normal controls were selected in the Obstetrics and Gynecology of Qingdao Municipal Hospital (Qingdao, China), between May 2014 and December 2014. The criteria used for diagnosis of pre-eclampsia were as follows: i) Systolic blood pressure of $\geq 140 \mathrm{~mm} \mathrm{Hg}$ or diastolic blood pressure of $\geq 90 \mathrm{~mm} \mathrm{Hg}$ occurring 20 weeks post-gestation in a woman whose blood pressure was previously normal; and ii) proteinuria, with excretion of $\geq 0.3 \mathrm{~g}$ in a $24-h$ period. All studied pregnant women had given birth via cesarean section and no significant difference $(\mathrm{P}>0.05)$ in age (20-35 years old) and gestational age (35-40 weeks) was exhibited between the patients of the PE group and the control group. All specimen collections were approved by the Ethics Committee of Qingdao Municipal Hospital and all subjects gave their informed written consent. All cases were confirmed by pathology, following surgery. Placental tissue samples were collected during cesarean section and immediately stored at $-80^{\circ} \mathrm{C}$ for detection by reverse transcription-quantitative polymerase chain reaction (RT-qPCR) and western blotting. The present study was approved by the Ethics Review Board of Qingdao Municipal Hospital.
Reagents. Normal human trophoblast cell line (HTR-8/SVneo) cells were purchased from American Type Culture Collection (Manassas, VA, USA). TRIzol and Lipofectamine 2000 were purchased from Invitrogen (Thermo Fisher Scientific, Inc., Waltham, MA, USA). miR-18b mimics/inhibitors were purchased from Shanghai GenePharma Co., Ltd. (Shanghai, China). Rabbit anti-human HIF-1 $\alpha$ polyclonal antibody was purchased from Abcam (ab82832; Cambridge, MA, USA). The reverse transcription kit, SYBR PrimeScript miRNA RT-PCR kit and SYBR-Green real-time PCR reagents were all purchased from Takara Biotechnology Co., Ltd. (Dalian, China).

Cell culture and transfection. HTR-8/SVneo cells were cultured in Dulbecco's modified Eagle's medium (DMEM)-F12 complete culture medium (Hyclone, Logan, UT, USA) supplemented with $20 \%$ fetal bovine serum (FBS; Sijiqing, Hangzhou, China) at $4 \times 10^{5}$ per well and maintained at $37^{\circ} \mathrm{C}$ in a humidified atmosphere of $5 \% \mathrm{CO}_{2}$ and $20 \% \mathrm{O}_{2}$. For transfection, HTR-8/SVneo cells were seeded in 6-well plates and cell transfection was performed when $\sim 70 \%$ confluency was achieved. Four groups were allocated, consisting of the hsa-miR-18b mimic transfected group (transfected with mimic), hsa-miR-18b inhibitor transfected group (transfected with inhibitor), negative control transfected group (transfected with negative controls) and non-transfected control group (blank/no transfection preformed). Lipofectamine 2000 transfection reagents were used for transfection. Cells were harvested at $48 \mathrm{~h}$ following transfection.

RNA extraction and reverse transcription. Total RNA were extracted from placental tissues and HTR-8/SVneo cells using the TRIzol and phenol chloroform method. RNA was reverse transcribed into cDNA, and the cDNA was stored at $-20^{\circ} \mathrm{C}$. For miRNA reverse transcription, the reverse transcription system consisted of $6 \mu 1 \mathrm{RNA}, 10 \mu \mathrm{l}$ miRNA reaction buffer mix (2X), $2 \mu \mathrm{l}$ BSA $(0.1 \%)$ and $2 \mu \mathrm{l}$ miRNA PrimeScript RT Enzyme mix. Reverse transcription was performed at $37^{\circ} \mathrm{C}$ for $60 \mathrm{~min}$.

$R T-q P C R$ analysis. mRNA expression levels of miR-18b and HIF-1 $\alpha$ in tissues and HTR-8/SVneo cells were detected by SYBR-Green quantitative PCR. U6 and GAPDH were used as internal controls of miR-18b and HIF-1 $\alpha$, respectively. RT-qPCR for miR-18b was performed in $25 \mu \mathrm{l}$ of reaction system containing 12.5 $\mu \mathrm{l}$ SYBR Premix Ex Taq, $0.5 \mu \mathrm{l}$ forward primer (5'-UAAGGUGCAUCUAGUGCAGUUAG-3'), $1 \mu 1$ Uni-miR qPCR primer (5'-CCAUAAGGUGCAUCUAGUGCAGU-3'), $2 \mu \mathrm{l}$ template and $8.5 \mu \mathrm{l}$ double-distilled $\mathrm{H}_{2} \mathrm{O}$. RT-qPCR for miR-18b was performed using a verititm 96-well thermal cycler (Applied Biosystems; Thermo Fisher Scientific, Inc.) using the following procedure: $95^{\circ} \mathrm{C}$ for $30 \mathrm{sec}$, followed by 40 cycles of $94^{\circ} \mathrm{C}$ for $5 \mathrm{sec}$ and $60^{\circ} \mathrm{C}$ for $20 \mathrm{sec}$. RT-qPCR for $\mathrm{HIF}-1 \alpha$ was performed in a $20-\mu 1$ reaction mixture containing $10 \mu \mathrm{l}$ SYBR Premix Ex Taq, $0.5 \mu \mathrm{l}$ forward primer (5'-TCAAAGTCGGACAGCCTCAC-3'), $0.5 \mu$ l reverse primer (5'-TAGCTGCATGATCGTCTGGC-3'), $1 \mu$ l cDNA template and $8 \mu \mathrm{l}$ double-distilled $\mathrm{H}_{2} \mathrm{O}$. RT-qPCR for HIF- $1 \alpha$ was performed using the following procedure: $95^{\circ} \mathrm{C}$ for $10 \mathrm{~min}$, followed by 40 cycles of $94^{\circ} \mathrm{C}$ for $1 \mathrm{~min}, 60^{\circ} \mathrm{C}$ for $40 \mathrm{sec}$ and $72^{\circ} \mathrm{C}$ for $40 \mathrm{sec}$. Each experiment was performed in triplicate. 
The relative expression of HIF-1 $\alpha$ was calculated using the $2^{-\Delta \Delta C q}$ method (23).

Western blotting. Total proteins $(50 \mu \mathrm{g})$ were extracted from placental tissues and HTR-8/SVneo cells by incubating with pre-cold RIPA lysate (50 mM Tris-base, $1 \mathrm{mM}$ EDTA, $150 \mathrm{mM}$ $\mathrm{NaCl}, 0.1 \%$ SDS, $1 \%$ Triton $\mathrm{X}-100$ and $1 \%$ sodium deoxycholate). The concentration of protein was determined using a BCA Protein Assay kit (Beyotime Institute of Biotechnology, Shanghai, China). Proteins of $10 \mu \mathrm{l}$ were subjected to a $12 \%$ SDS-PAGE electrophoresis $(100 \mathrm{~V})$ and transferred to a PVDF membrane (Merck Millipore, Darmstadt, Germany). The membrane was blocked with 5\% skimmed milk in Tris-buffered saline with $0.1 \%$ Tween-20 for $1 \mathrm{~h}$ at room temperature. The primary antibodies anti-HIF-1 $\alpha$ (ab113642; 1:1,000; Abcam) and anti-GAPDH (ab8245; 1:2,000; Abcam) for detecting the expression of endogenous GAPDH as an internal reference were incubated at $4{ }^{\circ} \mathrm{C}$ overnight. After washing with PBS with Tween-20 for 15 min three times, the secondary antibodies horseradish peroxidase-conjugated goat anti-rabbit antibodies (ab6789, 1:1,000, Abcam) were added and incubated for $1 \mathrm{~h}$ at room temperature and then washed by PBS with Tween-20 for $15 \mathrm{~min}$ three times. Chemiluminescence reagent (EMD Millipore, Billerica, MA, USA) was used for color development. The protein was placed in the ECL luminescent solution and the image signal was obtained and analyzed by the image lab software (Bio-Rad Laboratories, Inc., Hercules, CA, USA). The gray value of the target protein band was compared with that of the GAPDH. The ratio of the gray value of the band is the relative content of the target protein.

Cell migration. Effects of miR-18b on the migration of HTR-8/SVneo cells were measured using a Transwell chambers assay (Corning Inc., Corning, NY, USA). Transfected cells were trypsinized, resuspended to $5 \times 10^{5}$ cells $/ \mathrm{ml}$ in DMEM supplemented with $0.1 \%$ bovine serum albumin (BSA). Cells (200 $\mu \mathrm{l}$ with the density of $5 \times 10^{5}$ cells $/ \mathrm{ml}$ ) were added to the upper compartment of the chamber. To the lower compartment, DMEM supplemented with $20 \%$ FBS was added as the chemotactic factor. Once incubated at $37^{\circ} \mathrm{C}$ for $4 \mathrm{~h}$, cells inside the upper compartment of the chamber were wiped and the cells migrated through to the lower compartment of the chamber were fixed with $100 \%$ methanol. Evaluation of migrated cells was performed under a light microscope at a magnification of x400 following $0.1 \%$ crystal violet cell staining.

MTT assay. The effect of miR-18b on total cellular metabolic activity of HTR-8/SVneo cells was studied using an MTT Cell Viability Assay kit (Beyotime Institute of Biotechnology). HTR-8/SVneo cells were cultured in DMEM supplemented with $10 \% \mathrm{BSA}$ at $37^{\circ} \mathrm{C}$ in a humidified atmosphere containing $5 \% \mathrm{CO}_{2}$. Subsequently, cells were transfected with hsa-miR-18b mimic, hsa-miR-18b inhibitors, negative control vector or not transfected (blank used for comparison) in 96-well plates at a density of 3,000 cells/well using Lipofectamine 2000, according to the manufacturer's instructions. For the MTT assay, each sample was provided with three parallel wells and $15 \mu \mathrm{l}$ of MTT was added to each well at 24,48 and $72 \mathrm{~h}$ following transfection. Following 4 -h incubation at $37^{\circ} \mathrm{C}$, the supernatant was removed, dimethyl sulfoxide (10 $\mu \mathrm{l} /$ well) was added and incubated at $37^{\circ} \mathrm{C}$ for $4 \mathrm{~h}$ to dissolve the purple formazan and the absorbance value of each well was read at a wavelength of $492 \mathrm{~nm}$.

Cell invasion assay. The invasive ability of HTR-8/SVneo cells (ATCC) seeded in 24-well plates was examined using growth factor-depleted matrigel invasion chambers (BD Biosciences, San Jose, CA, USA) and Transwell inserts (Corning, Inc., NY, USA). A total of $500 \mu 1$ serum-free DMEM (HyClone) was added to Matrigel chambers, incubated at room temperature for $1 \mathrm{~h}$ to hydrate matrix glue and the remaining medium was removed. Subsequently, $750 \mu$ l DMEM supplemented with $20 \%$ FBS (Sijiqing, Hangzhou, China) was added to the lower chamber. Cells were transfected with hsa-miR-18b mimic, hsa-miR-18b inhibitors, negative control vector or not transfected (blank). Transfected cells were trypsinized, centrifugally collected and resuspended to $4 \times 10^{5}$ cells $/ \mathrm{ml}$ in DMEM supplemented with $0.1 \%$ BSA. Cells (500 $\mu \mathrm{l}$ with the density of $4 \times 10^{5}$ cells $/ \mathrm{ml}$ ) were added to the upper compartment of the chamber. Following incubation at $37^{\circ} \mathrm{C}$ in a humidified atmosphere containing $5 \% \mathrm{CO}_{2}$ for $18 \mathrm{~h}$, the cells inside the upper compartment of the chamber were wiped using a cotton swab and the cells invaded through to the lower compartment of the chamber with $100 \%$ methanol were fixed. Evaluation of migrated cells was performed under a light microscope following $0.1 \%$ crystal violet (Beyotime Institute of Biotechnology) cell staining.

Statistical analysis. All statistical analyses were performed using Statistical Package for Social Sciences software for Windows (version 16.0; SPSS, Inc., Chicago, IL, USA). Each experiment was repeated in triplicate $(n=3)$. Data are presented as mean \pm standard deviation. All data were analyzed with a normality test. Variance analysis was applied for multiple sets of measurement data analysis and Student's t-test was applied for two sets of data analysis. $\mathrm{P}<0.05$ was considered to indicate a statistically significant difference.

\section{Results}

Expression levels of miR-18b and HIF-1 $\alpha$ in PE and normal placental tissues detected by RT-qPCR. mRNA expression levels of miR-18b and HIF- $1 \alpha$ in PE and normal placental tissues were detected by RT-qPCR. As indicated in Fig. 1, the mRNA expression levels of HIF-1 $\alpha$ mRNA in PE placental tissues were significantly increased when compared with normal placental tissues $(\mathrm{P}<0.05$; Fig. $1 \mathrm{~A})$ and the mRNA expression levels of miR-18b in PE placental tissues were significantly decreased when compared with normal placental tissues $(\mathrm{P}<0.05$; Fig. 1B). These results indicate that the downregulated $\mathrm{mRNA}$ expression levels of miR-18b may be related to the presence of HIF-1 $\alpha$ in placental tissues.

Prediction of hsa-miR-18b target genes. Target genes of hsa-miR-18b were predicted using TargetScan software (http://www.targetscan.org/) as described previously (24). Results indicated a targeted regulatory relationship between HIF- $1 \alpha$ and miR-18b and the specific regulatory binding sequences were shown in Fig. 2. The present finding suggests that HIF-1 $\alpha$ is one of the target genes of miR-18b. 
$\mathbf{A}$

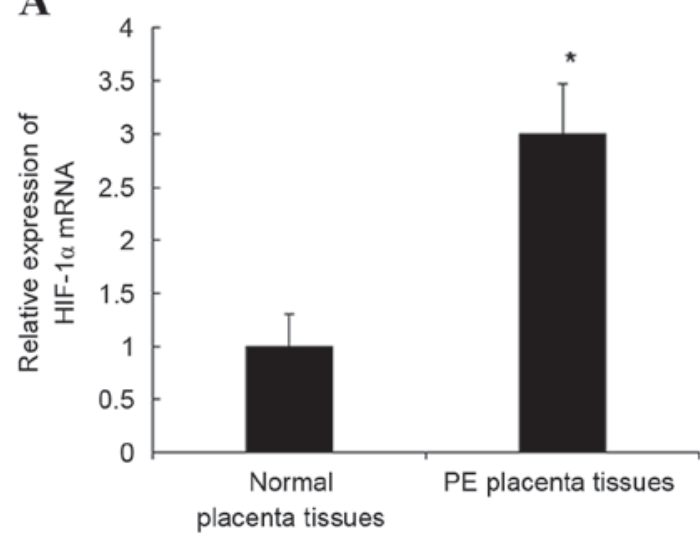

B

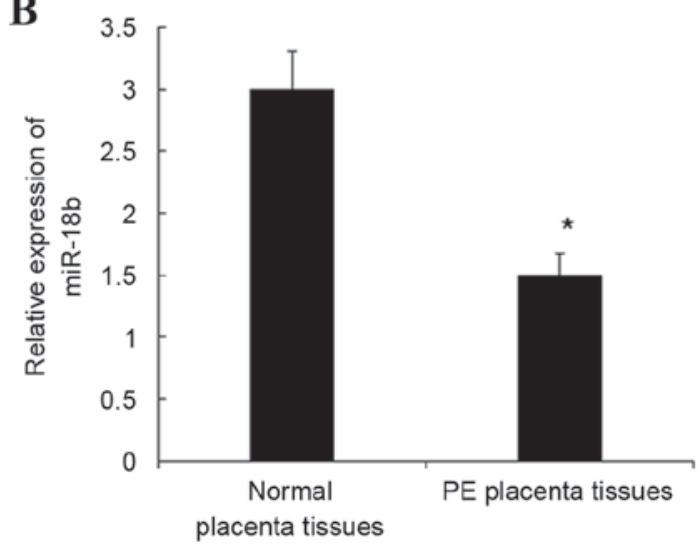

Figure 1. Expression of (A) HIF-1 $\alpha$ and (B) miR-18b in PE and normal placental tissues detected by reverse transcription-quantitative polymerase chain reaction. ${ }^{*} \mathrm{P}<0.05$ vs. normal placental tissues. HIF-1 $\alpha$, hypoxia inducible factor-1 $\alpha$; PE, preeclampsia; miR-18b, microRNA $18 b$.

\section{HIF-1 $\alpha$ mRNA (NM_181054): $\quad 5 \cdots$ AAAA A ATG CACC TTTT TATT $\cdots \cdot 3$ III IIII II \\ hsa-miR-18b : \\ 3' GAUU GACG UGAU C UAC GUGG AAU 5'}

Figure 2. Predicted specific regulatory binding sequences of miR-18b to HIF-1 $\alpha$ using Targetscan software. HIF-1 $\alpha$, hypoxia inducible factor- $1 \alpha$ miR-18b, microRNA 18b.

Protein expression of HIF-1 $\alpha$ in placental tissues. Protein expression levels of HIF-1 $\alpha$ in PE and normal placental tissues were detected by western blotting. Consistent with the trend observed for HIF-1 $\alpha$ mRNA expression, the protein expression levels of HIF-1 $\alpha$ in PE placental tissues were significantly increased when compared with normal placental tissues ( $\mathrm{P}<0.05$; Fig. 3). This result indicates that the abnormal expression of HIF-1 $\alpha$ is closely related to the occurrence of PE.

Expression of HIF-1 $\alpha$ in transfected HTR-8/SVneo cells. To verify the regulation of miR-18b on the expression of HIF- $1 \alpha$ gene, mRNA expression levels of HIF-1 $\alpha$ in hsa-miR-18b mimic-transfected, hsa-miR-18b inhibitor-transfected and negative control vector-transfected HTR-8/SVneo cells (NC) and normal HTR-8/SVneo cells (blank) were compared by RT-qPCR. mRNA expression levels of miR-18b were significantly increased in miR-18b mimic transfected HTR-8/SVneo cells, which were $>1.7$-fold higher when compared with the NC and blank groups $(\mathrm{P}<0.05$; Fig. $4 \mathrm{~A})$. Furthermore, the mRNA expression levels of miR-18b were significantly decreased in miR-18b inhibitor-transfected HTR-8/SVneo cells, which were $<30 \%$ of the mRNA expression levels exhibited by miR-18b in the NC and blank groups $(\mathrm{P}<0.05$; Fig. 4A). Moreover, the mRNA and protein expression levels of HIF-1 $\alpha$ gene were compared. When compared with the expression levels exhibited in the NC and blank groups, overexpression of miR-18b resulted in significantly decreased expression levels of HIF-1 $\alpha$ in HTR-8/SVneo cells at protein $(\mathrm{P}<0.05$; Fig. $4 \mathrm{~B}$ and $\mathrm{C})$ and mRNA level $(\mathrm{P}<0.05$; Fig. 4D). Conversely, inhibited expression of miR-18b resulted in significantly increased expression levels of HIF-1 $\alpha$ in HTR-8/SVneo cells at protein $(\mathrm{P}<0.05$; Fig. 4B and $\mathrm{C}$ ) and mRNA level ( $\mathrm{P}<0.05$; Fig. 4D). These results suggest that overexpression of miR-18b may inhibit the transcription and translation of HIF-1 $\alpha$ gene.
miR-18b inhibits cell migration and invasion ability of HTR-8/SVneo cells. Possible effects of miR-18b on the cell migration and invasion ability of HTR-8/SVneo cells were studied using the cell migration and invasion assay. When compared with the NC and blank groups, overexpression of miR-18b resulted in significantly decreased cell migration and invasion abilities of HTR-8/SVneo cells $(\mathrm{P}<0.05$; Fig. 5); however, inhibited expression of miR-18b resulted in significantly increased cell migration and invasion abilities of HTR-8/SVneo cells ( $\mathrm{P}<0.05$; Fig. 5). These results suggest that miR-18b may inhibit the cell migration and invasion abilities of HTR-8/SVneo cells.

miR-18b inhibits total cellular metabolic activity of HTR-8/SVneo cells. Possible effects of miR-18b on the total cellular metabolic activity of HTR-8/SVneo cells were studied using MTT assays. When compared with the NC and blank groups, overexpression of miR-18b resulted in significantly decreased total cellular metabolic activity of HTR-8/SVneo cells; however, inhibited expression of miR-18b resulted in significantly increased total cellular metabolic activity of HTR-8/SVneo cells $(\mathrm{P}<0.05$; Fig. 6). These results indicate that miR-18b may inhibit the total cellular metabolic activity of HTR-8/SVneo cells.

\section{Discussion}

It has been reported that abnormalities of placental trophoblast cells may be associated with the pathogenesis of PE $(25,26)$. Invasion disorder of trophoblast cells is a central link in the development of PE and placenta ischemia, and hypoxia of PE has been indicated to further aggravate the invasion disorder of trophoblast cells, subsequently forming a vicious cycle (27).

HIF- $1 \alpha$ is able to regulate the transcription of various hypoxia-sensitive factor genes (28). Studies have indicated that the 401 to 603 amino acid residues of HIF-1 $\alpha$ have an oxygen-dependent degradation domain $(29,30)$. Under normoxic conditions, HIF-1 $\alpha$ is degraded and therefore it is difficult to detect the presence of HIF-1 $\alpha$. However, in the case of hypoxia, the degradation of HIF-1 $\alpha$ is blocked and HIF- $1 \alpha$ accumulates in the nucleus (31). The accumulated HIF-1 $\alpha$ combines with HIF-1 $\beta$ in the nucleus to form HIF, 
A

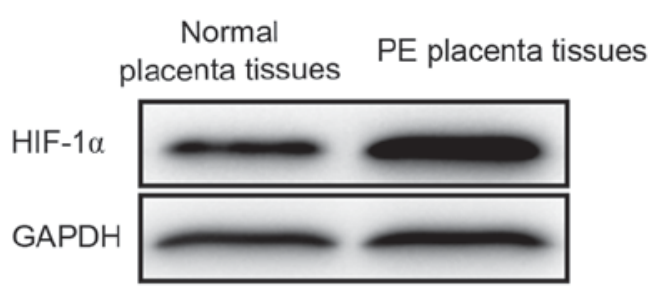

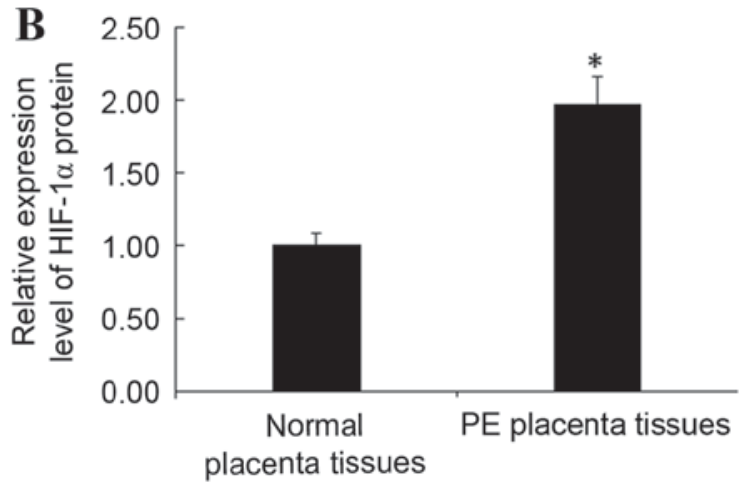

Figure 3. Expression of HIF-1 $\alpha$ protein in PE and normal placental tissues detected by western blotting. (A) Expression of HIF-1 $\alpha$ protein in PE and normal placental tissues. (B) Relative expression level of HIF-1 $\alpha$ protein in PE placental tissues to in normal placental tissues. " $\mathrm{P}<0.05$ vs. normal placental tissues. HIF-1 $\alpha$, hypoxia inducible factor-1 $\alpha$; PE, preeclampsia.
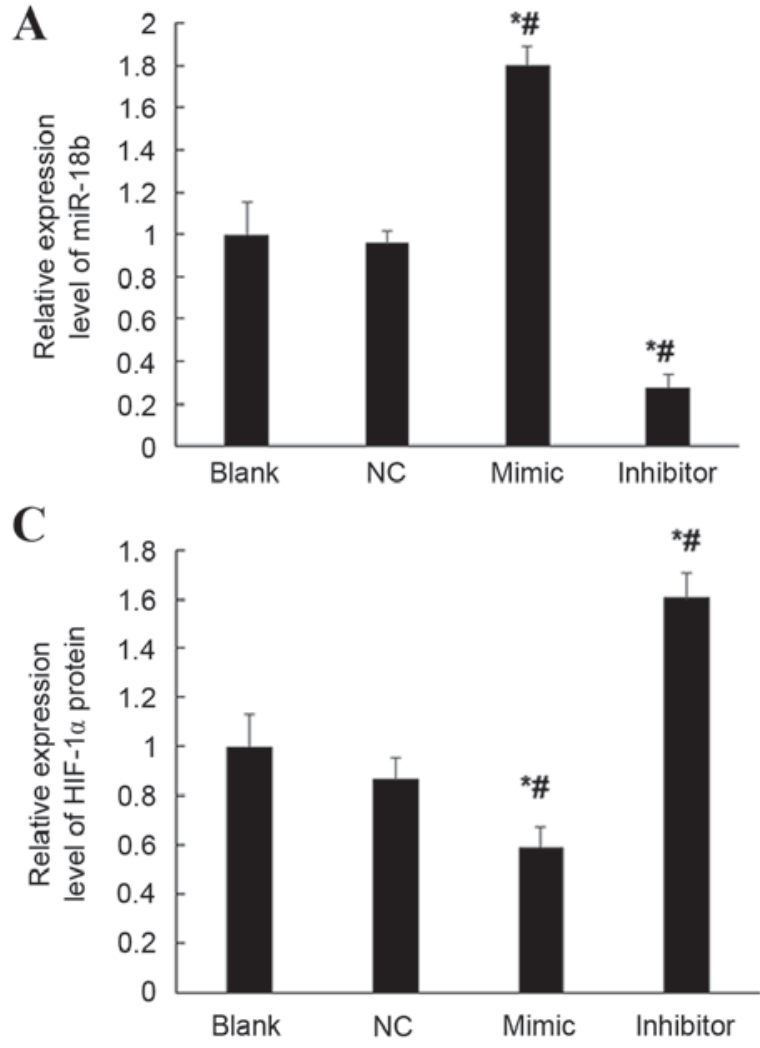

B

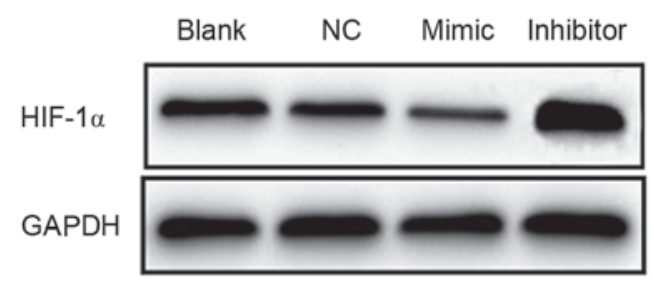

D

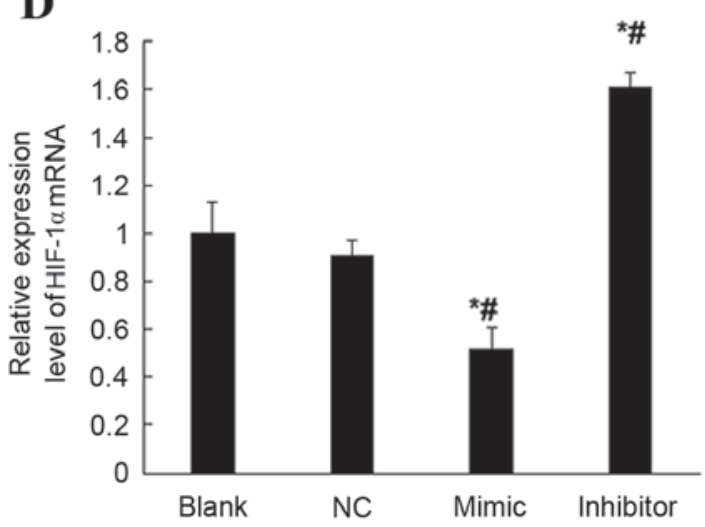

Figure 4. Expression of HIF-1 $\alpha$ and miR-18b in hsa-miR-30c mimic (mimic), hsa-miR-30c inhibitor (inhibitor), negative control transfected (NC) and non-transfected HTR-8/SVneo cells (blank) detected by reverse transcription- quantitative polymerase chain reaction and western blotting. (A) Relative mRNA expression levels of miR-18b in all groups of HTR-8/SVneo cells. (B) Expression levels of HIF-1 $\alpha$ protein in all groups of HTR-8/SVneo cells. GAPDH was used as a loading control. (C) Relative expression levels of HIF-1 $\alpha$ protein in all groups of HTR-8/SVneo cells. (D) Relative expression levels of HIF-1 $\alpha$ mRNA in all groups of HTR-8/SVneo cells. "P<0.05 vs. Blank. "P<0.05 vs. NC. HIF-1 $\alpha$, hypoxia inducible factor-1 $\alpha$; PE, preeclampsia; miR-18b, microRNA $18 b$.

which further activates the transcription and expression of hypoxia-sensitive factor genes by binding to the hypoxia response elements (32). HIF-1 is able to regulate the expression of various factors, such as the vascular endothelial growth factor (VEGF), VEGF receptors (33) and glucose transporters, which have important roles in erythropoiesis, cell proliferation and differentiation (34). In the present study, mRNA and protein expression levels of HIF-1 $\alpha$ in PE placental tissues were significantly higher than that in the normal population.

It remains unclear whether specific miRNA may participate in the pathogenesis of PE. Mature miRNA combine with other proteins to form miRNA-induced silencing complexes, recognize and bind to target genes by complete or incomplete complementary binding to the 3'-UTR of the target mRNA and regulate the expression of target genes (35). Pineles et al (36) reported that differential expression of miR-182 and miR-210 was exhibited in the placentas of PE patients and normal individuals. In addition, Zhu et al (37) indicated that the expression of 34 miRNA was disordered in PE placentas, including 23 miRNA upregulated and 11 downregulated. Further functional investigation in their study indicated that these miRNA have important roles in the process of placenta development 

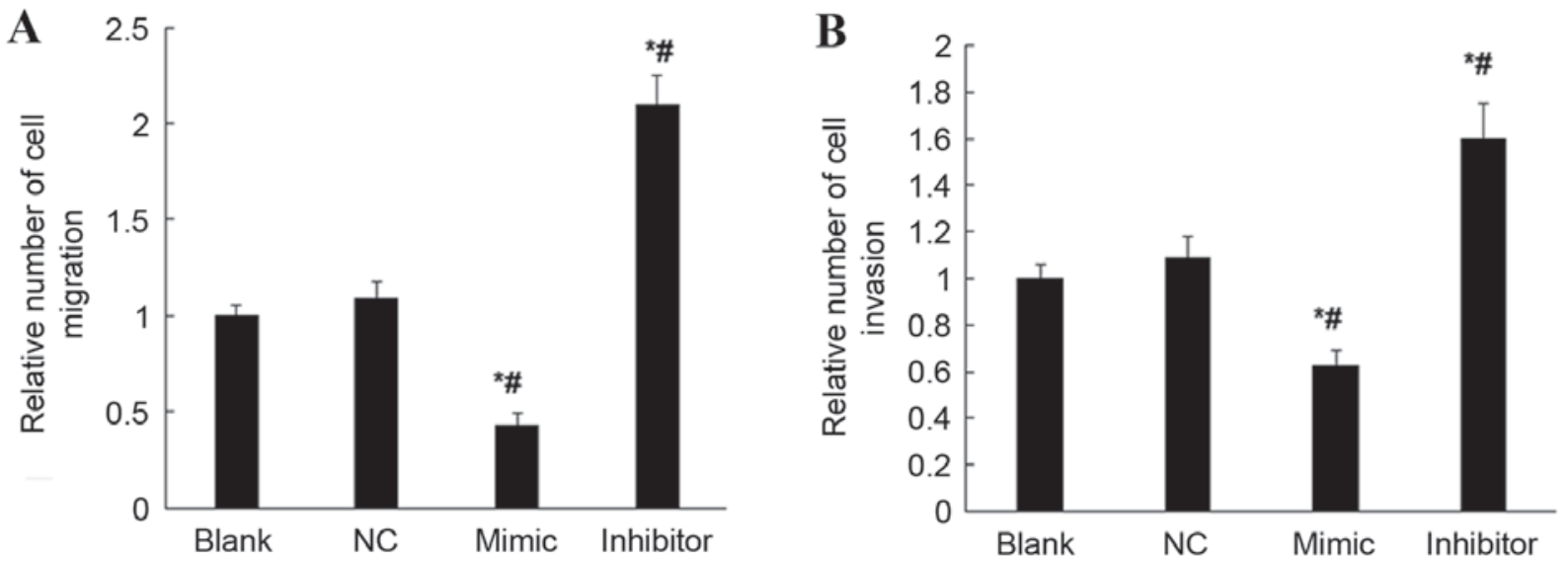

Figure 5. Cell migration and invasion of hsa-miR-18b mimic (mimic), hsa-miR-18b inhibitor (inhibitor), negative control transfected (NC) and non-transfected HTR-8/SVneo cells (blank) detected using the cell invasion assay. (A) Relative number of cell migration in all groups of HTR-8/SVneo cells. (B) Relative number of cell invasion in all groups of HTR-8/SVneo cells. ${ }^{*} \mathrm{P}<0.05$ vs. Blank. ${ }^{~} \mathrm{P}<0.05$ vs. NC. HIF-1 $\alpha$, hypoxia inducible factor-1 $\alpha$; miR-18b, microRNA $18 \mathrm{~b}$.

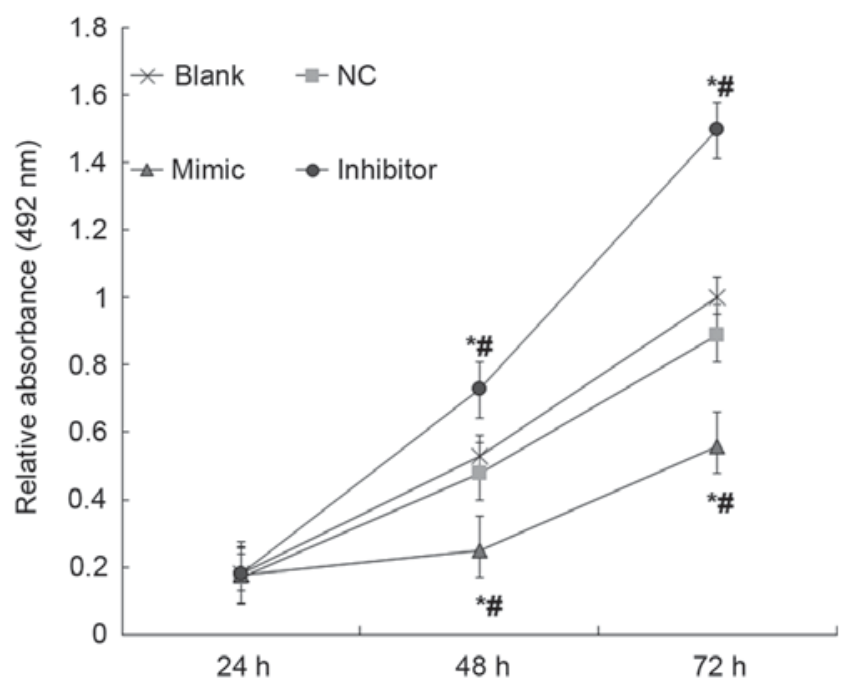

Figure 6. Relative absorbance of hsa-miR-18b mimic (mimic), hsa-miR-18b inhibitor (inhibitor), negative control transfected (NC) and non-transfected HTR-8/SVneo cells (blank). Total cellular metabolic activity was detected by MTT assay. ${ }^{*} \mathrm{P}<0.05$ vs. Blank. ${ }^{~} \mathrm{P}<0.05$ vs. NC. HIF- $1 \alpha$, hypoxia inducible factor-1 $\alpha$; miR-18b, microRNA $18 \mathrm{~b}$.

and PE occurrence and development (37). Wang et al revealed that miR-18b was highly expressed in non-metastatic colon cancer specimens by miRNA chip detection (38). Furthermore, a previous study demonstrated that the expression of miR-18b was elevated in human basal cell carcinoma, suggesting that miR-18b may be involved in the occurrence and development of basal cell carcinoma (39). It has been suggested that in different tissues, the function and expression of miR-18b may differ (40).

The villous trophoblast bilayer covering the placental villi consists of the underlying cytotrophoblast layer and outer syncytiotrophoblast layer. A population of cells, extravillous trophoblasts (EVTs), detach from placental villi in the first 20 weeks of pregnancy and invade the uterine wall, remodeling the maternal uterine arteries in normal pregnancy (41). HTR-8/SVneo cells are non-cancerous cells isolated from EVT (42). In the present study, HTR-8/SVneo cells were used to investigate the function of miR-18b in placenta trophoblast cells. miR-18b mimic and miR-18b inhibitor were transfected into HTR-8/SVneo cells and the changes of related cellular functions were studied. RT-qPCR results showed that the mRNA expression levels of miR-18b were significantly increased in miR-18b mimic-transfected cells and significantly decreased in miR-18b inhibitor-transfected cells, suggesting that miR-18b mimic and inhibitor were able to regulate the expression of miR-18b. Using RT-qPCR and western blotting, the present study revealed that overexpression of miR-18b significantly inhibited the expression of HIF-1 $\alpha$, whereas inhibition of miR-18b significantly increased the expression of HIF-1 $\alpha$ in HTR-8/SVneo cells. Subsequently, the effects of target regulation of $\mathrm{miR}-18 \mathrm{~b}$ on $\mathrm{HIF}-1 \alpha$ with respect to cell biological functions were further investigated and the mechanism of abnormal expression of miR-18b exhibited in the development of PE was explored. The present results indicated that, in miR-18b-overexpressing HTR-8/SVneo cells, the total cellular metabolic activity, migration and invasion ability were significantly decreased, whereas these abilities were significantly increased when the expression of miR-18b was inhibited. These results suggest that miR-18b may be involved in the development of $\mathrm{PE}$ through targeted regulation of HIF-1 $\alpha$, subsequently affecting the cell migration, invasion and viability of HTR-8/SVneo cells.

The present study exhibited some limitations. One limitation was that the HTR8-SVneo cell line, a model of primary EVT used in the present study, is proliferative and may behave differently to primary cells. Furthermore, miR-18b expression in human placental tissue was obtained at the end of pregnancy and not at the first 20 weeks of pregnancy, during which uterine spiral artery remodeling occurs. Therefore, whether altered miR-18b expression was the cause or the consequence of pre-eclampsia is unknown. Moreover, we did not further investigate the clinical implication of in vivo reduced miR-18b expression or evaluate the clinical benefits. Further studies are required to overcome these limitations.

In conclusion, we believe that the present study indicated that miR-18b may act as an inhibitory factor in the pathogenesis of PE, and that miR-18b and HIF-1 $\alpha$ have a critical role in the development of PE. We suggest that designing targeted therapies towards miR-18b and HIF-1 $\alpha$ and clinically 
monitoring the expression of miR-18b and HIF-1 $\alpha$ in placental tissue of PE patients may be helpful in improving the diagnosis and prognosis of $\mathrm{PE}$.

\section{Acknowledgements}

The authors would like to thank Professor Xianghong Ji (chief physician; Qingdao Municipal Hospital, Oingdao, China) for her valuable help to the present study.

\section{References}

1. Maynard SE, Min JY, Merchan J, Lim KH, Li J, Mondal S, Libermann TA, Morgan JP, Sellke FW, Stillman IE, et al: Excess placental soluble fms-like tyrosine kinase 1 (sFlt1) may contribute to endothelial dysfunction, hypertension, and proteinuria in preeclampsia. J Clin Invest 111: 649-658, 2003.

2. Caniggia I, Mostachfi H, Winter J, Gassmann M, Lye SJ, Kuliszewski M and Post M: Hypoxia-inducible factor-1 mediates the biological effects of oxygen on human trophoblast differentiation through TGFbeta(3). J Clin Invest 105: 577-587, 2000.

3. Allaire AD, Ballenger KA, Wells SR, McMahon MJ and Lessey BA: Placental apoptosis in preeclampsia. Obstet Gynecol 96: 271-276, 2000.

4. Pasquinelli AE: MicroRNAs and their targets: Recognition, regulation and an emerging reciprocal relationship. Nat Rev Genet 13: 271-282, 2012.

5. Rácz Z, Kaucsár T and Hamar P: The huge world of small RNAs: Regulating networks of microRNAs (review). Acta Physiol Hung 98: 243-251, 2011.

6. Schober A, Nazari-Jahantigh M, Wei Y, Bidzhekov K, Gremse F, Grommes J, Megens RT, Heyll K, Noels H, Hristov M, et al: MicroRNA-126-5p promotes endothelial proliferation and limits atherosclerosis by suppressing Dlk1. Nat Med 20: 368-376, 2014

7. Calin GA and Croce CM: MicroRNA signatures in human cancers. Nat Rev Cancer 6: 857-866, 2006.

8. Murphy MS, Casselman RC, Tayade C and Smith GN: Differential expression of plasma microRNA in preeclamptic patients at delivery and 1 year postpartum. Am J Obstet Gynecol 213 367.e1-e9, 2015.

9. Akehurst C, Small HY, Sharafetdinova L, Forrest R, Beattie W, Brown CE, Robinson SW, McClure JD, Work LM, Carty DM, et al: Differential expression of microRNA-206 and its target genes in preeclampsia. J Hypertens 33: 2068-2074, 2015.

10. Enquobahrie DA, Abetew DF, Sorensen TK, Willoughby D, Chidambaram K and Williams MA: Placental microRNA expression in pregnancies complicated by preeclampsia. Am J Obstet Gynecol 204: 178.e12-e21, 2011.

11. Dar AA, Majid S, Rittsteuer C, de Semir D, Bezrookove V, Tong S, Nosrati M, Sagebiel R, Miller JR III and Kashani-Sabet M: The role of miR-18b in MDM2-p53 pathway signaling and melanoma progression. J Natl Cancer Inst 105: 433-442, 2013.

12. Guo J, Miao Y, Xiao B, Huan R, Jiang Z, Meng D and Wang Y: Differential expression of microRNA species in human gastric cancer versus non-tumorous tissues. J Gastroenterol Hepatol 24: 652-657, 2009

13. Yoshimoto N, Toyama T, Takahashi S, Sugiura H, Endo Y, Iwasa M, Fujii Y and Yamashita H: Distinct expressions of microRNAs that directly target estrogen receptor $\alpha$ in human breast cancer. Breast Cancer Res Treat 130: 331-339, 2011.

14. Yu X, Zhen Y, Yang H, Wang H, Zhou Y, Wang E, Marincola FM, Mai C, Chen Y, Wei H, et al: Loss of connective tissue growth factor as an unfavorable prognosis factor activates miR-18b by $\mathrm{PI} 3 \mathrm{~K} / \mathrm{AKT} / \mathrm{C}$-Jun and C-Myc and promotes cell growth in nasopharyngeal carcinoma. Cell Death Dis 4: e634, 2013.

15. Zhang C, Li Q, Ren N, Li C, Wang X, Xie M, Gao Z, Pan Z, Zhao C, Ren C and Yang W: Placental miR 106a-363 cluster is dysregulated in preeclamptic placenta. Placenta 36: 250-252, 2015

16. Semenza G: Signal transduction to hypoxia-inducible factor 1. Biochem Pharmacol 64: 993-998, 2002.

17. Semenza GL: Defining the role of hypoxia-inducible factor 1 in cancer biology and therapeutics. Oncogene 29: 625-634, 2010.

18. Semenza GL: HIF-1, O(2), and the 3 PHDs: How animal cells signal hypoxia to the nucleus. Cell 107: 1-3, 2001

19. Taylor CT: Mitochondria and cellular oxygen sensing in the HIF pathway. Biochem J 409: 19-26, 2008.
20. Ietta $\mathrm{F}, \mathrm{Wu} \mathrm{Y}$, Winter J, Xu J, Wang J, Post M and Caniggia I: Dynamic HIF1A regulation during human placental development. Biol Reprod 75: 112-121, 2006.

21. Nevo O, Soleymanlou N, Wu Y, Xu J, Kingdom J, Many A, Zamudio S and Caniggia I: Increased expression of sFlt-1 in in vivo and in vitro models of human placental hypoxia is mediated by HIF-1. Am J Physiol Regul Integr Comp Physiol 291: R1085-R1093, 2006

22. Aplin JD: Hypoxia and human placental development. J Clin Invest 105: 559-560, 2000.

23. Livak KJ and Schmittgen TD: Analysis of relative gene expression data using real-time quantitative PCR and the 2(-Delta Delta C(T)) method. Methods 25: 402-408, 2001.

24. Lewis BP, Burge CB and Bartel DP: Conserved seed pairing, often flanked by adenosines, indicates that thousands of human genes are microRNA targets. Cell 120: 15-20, 2005.

25. Goldman-Wohl D and Yagel S: Preeclampsia-a placenta developmental biology perspective. J Reprod Immunol 82: 96-99, 2009.

26. Shah DM: Preeclampsia: New insights. Curr Opin Nephrol Hypertens 16: 213-220, 2007.

27. Granger JP, Alexander BT, Llinas MT, Bennett WA and Khalil RA: Pathophysiology of preeclampsia: Linking placental ischemia/hypoxia with microvascular dysfunction. Microcirculation 9: 147-160, 2002.

28. Qiang L, Wu T, Zhang HW, Lu N, Hu R, Wang YJ, Zhao L, Chen FH, Wang XT, You QD and Guo QL: HIF-1 $\alpha$ is critical for hypoxia-mediated maintenance of glioblastoma stem cells by activating Notch signaling pathway. Cell Death Differ 19: 284-294, 2012

29. Huang LE, Gu J, Schau M and Bunn HF: Regulation of hypoxia-inducible factor 1alpha is mediated by an $\mathrm{O} 2$-dependent degradation domain via the ubiquitin-proteasome pathway. Proc Natl Acad Sci USA 95: 7987-7992, 1998.

30. Ivan M, Kondo K, Yang H, Kim W, Valiando J, Ohh M, Salic A, Asara JM, Lane WS and Kaelin WG Jr: HIFalpha targeted for VHL-mediated destruction by proline hydroxylation: Implications for O2 sensing. Science 292: 464-468, 2001.

31. Weidemann A and Johnson RS: Biology of HIF-1alpha. Cell Death Differ 15: 621-627, 2008.

32. Wenger RH, Stiehl DP and Camenisch G: Integration of oxygen signaling at the consensus HRE. Sci STKE 2005: re12, 2005.

33. Jung JE, Lee HG, Cho IH, Chung DH, Yoon SH, Yang YM, Lee JW, Choi S, Park JW, Ye SK and Chung MH: STAT3 is a potential modulator of HIF-1-mediated VEGF expression in human renal carcinoma cells. FASEB J 19: 1296-1298, 2005.

34. Liu W, Shen SM, Zhao XY and Chen GQ: Targeted genes and interacting proteins of hypoxia inducible factor-1. Int J Biochem Mol Biol 3: 165-178, 2012.

35. Williams PJ and Broughton Pipkin F: The genetics of pre-eclampsia and other hypertensive disorders of pregnancy. Best Pract Res Clin Obstet Gynaecol 25: 405-417, 2011.

36. Pineles BL, Romero R, Montenegro D, Tarca AL, Han YM, Kim YM, Draghici S, Espinoza J, Kusanovic JP, Mittal P, et al: Distinct subsets of microRNAs are expressed differentially in the human placentas of patients with preeclampsia. Am J Obstet Gynecol 196: 261.e1-e6, 2007.

37. Zhu XM, Han T, Sargent IL, Yin GW and Yao YQ: Differential expression profile of microRNAs in human placentas from preeclamptic pregnancies vs normal pregnancies. Am J Obstet Gynecol 200: 661.e1-e7, 2009.

38. Wang YX, Zhang XY, Zhang BF, Yang CQ, Chen XM and Gao HJ: Initial study of microRNA expression profiles of colonic cancer without lymph node metastasis. J Dig Dis 11: 50-54, 2010.

39. Sand M, Skrygan M, Sand D, Georgas D, Hahn SA, Gambichler T, Altmeyer P and Bechara FG: Expression of microRNAs in basal cell carcinoma. Br J Dermatol 167: 847-855, 2012.

40. Calin GA, Sevignani C, Dumitru CD, Hyslop T, Noch E, Yendamuri S, Shimizu M, Rattan S, Bullrich F, Negrini $M$ and Croce CM: Human microRNA genes are frequently located at fragile sites and genomic regions involved in cancers. Proc Natl Acad Sci USA 101: 2999-3004, 2004.

41. Harris LK: Review: Trophoblast-vascular cell interactions in early pregnancy: how to remodel a vessel. Placenta 31 (Suppl): 93-98, 2010.

42. Graham CH, Hawley TS, Hawley RG, MacDougall JR, Kerbel RS, Khoo N and Lala PK: Establishment and characterization of first trimester human trophoblast cells extended with lifespan. Exp Cell Res 206: 204-211, 1993. 